\title{
2 Chemical Composition and Phase Evolution in \\ 3 DMAI-Derived Inorganic Perovskite Solar \\ 4 Cells
}

5 Hongguang Meng, ${ }^{[a, d] \dagger}$ Zhipeng Shao, ${ }^{[a]}{ }^{\dagger}$ Li Wang, ${ }^{[b]}$ Zhipeng Li, ${ }^{[a]}$ Ranran Liu, ${ }^{[a, b]}$

6 Yingping Fan, ${ }^{[a, b]}$ Guanglei Cui, ${ }^{[a]}$, * Shuping Pang ${ }^{[a, c]}$, *

7 [a] Qingdao Institute of Bioenergy and Bioprocess Technology, Chinese Academy of

8 Sciences, Qingdao 266101, P.R. China

9 [b] Qingdao University of Science and Technology, 266042, P.R. China

10 [c] Dalian National Laboratory for Clean Energy, Dalian 116023, P.R. China

11 [d] Center of Materials Science and Optoelectronics Engineering, University of

12 Chinese Academy of Sciences, Beijing 100049, P.R. China

13

14 †These authors contribute equally.

15 Corresponding Author

16 E-mail: cuigl@qibebt.ac.cn (G.C.); pangsp@qibebt.ac.cn (S.P.) 
2 Materials Synthesis: $\mathrm{PbI}_{2}, \mathrm{CsI}$, and DMAI were purchased from TCI. Others were

3 purchased from Sigma-Aldrich without further purification. The DMAI-CsPbI 3

4 precursor was prepared by dissolving $1 \mathrm{mmol} \mathrm{DMAI,} 1 \mathrm{mmol} \mathrm{CsI}$ and $1 \mathrm{mmol} \mathrm{PbI}_{2}$ in

$5 \quad 0.7 \mathrm{~mL}$ DMSO. Then stirred at $70{ }^{\circ} \mathrm{C}$ for $1 \mathrm{~h}$. Then the perovskite solution was spin-

6 coated on the substrates in a two-steps process at $1000 \mathrm{rpm}$ and $5000 \mathrm{rmp}$ for $10 \mathrm{~s}$ and

7 30s, respectively. The films were then dried at $100{ }^{\circ} \mathrm{C}$ for $15 \mathrm{~min}$. For mixed cation

8 perovskite films, those dried films were then annealed at $180^{\circ} \mathrm{C}$. For $\mathrm{CsPbI}_{3}$ perovskite

9 films, those dried films were then annealed at $350{ }^{\circ} \mathrm{C}$ for $15 \mathrm{~min}$.

10 Device Fabrication: The etched FTO was cleaned with ultrasonic washing in saturated

$11 \mathrm{KOH}$ isopropanol solution, deionized water and ethanol. After cleaning, a 20nm thick

12 compact $\mathrm{TiO}_{2}$ hole-blocking layer was deposited on the FTO by atomic layer deposition

13 (ALD). Subsequently, a 150-nm thick $\mathrm{TiO}_{2}$ porous layer was deposited on the compact

$14 \mathrm{TiO}_{2}$ by spin-coating followed by a heat-treatment at $500{ }^{\circ} \mathrm{C}$ for $30 \mathrm{~min}$ in air. The

15 porous $\mathrm{TiO}_{2}$ precursor solution was prepared by diluting the $\mathrm{TiO}_{2}$ paste (30NRT from

16 Dysol) in ethanol with a ratio of 1:6 w/w. Then the perovskite solution was spin-coated

17 on the substrates and annealed. After the perovskite layer cooling to room temperature,

$1830 \mu \mathrm{L}$ of Spiro-OMeTAD solution was deposited by spin-coating (3000 rpm, $30 \mathrm{~s}$ ).

19 Finally, $100 \mathrm{~nm}$ thick $\mathrm{Au}$ electrodes were thermally evaporated under vacuum to

20 complete the PSC fabrication. The Spiro-OMeTAD hole-transporting layer was

21 prepared by dissolving $72.3 \mathrm{mg}$ of Spiro-OMeTAD in $1 \mathrm{~mL}$ of chlorobenzene, in which 
$128.8 \mu \mathrm{L}$ of 4-tert-butylpyridine and $17.5 \mu \mathrm{L}$ of lithium bis(trifluoro-methanesulfonyl)

2 imide (LITSFI) solution (520 mg LITSFI in $1 \mathrm{~mL}$ acetonitrile) was added.

3 Materials and Device Characterization: XRD spectra were measured by a Bruker-AXS

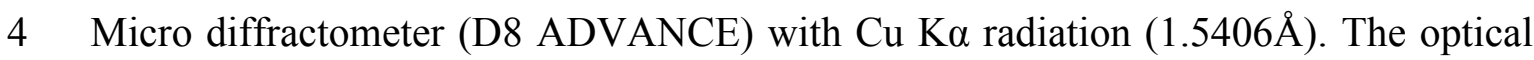

5 absorption spectra were measured by UV-vis/NIR spectrophotometer (U-4100,

6 Hitachi). Top-view SEM measurement was obtained with a field-emission scanning

7 electron microscope (S-4800, Hitachi). Thermogravimetric analysis (TG) was

8 conducted with a thermogravimetric analyzer (TGA Q50 V20.10 Build 36, TA

9 Instruments). PL spectra were taken on a Horiba LabRAM HR equipped with a diode

10 continuous-wave laser $(450 \mathrm{~nm})$ and a Synapse charge-coupled device camera. I-V

11 curves of the as-fabricated PSCs were measured using a 2400 Sourcemeter (Keithley,

12 USA) under simulated one-sun AM 1.5G $100 \mathrm{~mW} \mathrm{~cm}^{-2}$ intensity (Oriel Sol3A Class

13 AAA, Newport, USA). The typical active area of PSCs is $0.09 \mathrm{~cm}^{2}$ defined by a metal

14 mask. The intensity of the one-sun AM 1.5G illumination was calibrated using a Si-

15 reference cell certified by the National Renewable Energy Laboratory.

\section{Calculation of $\mathbf{D M A}_{\mathbf{x}} \mathbf{C s}_{1-\mathbf{x}} \mathbf{P b I}_{3}$}

17 The TG result in Figure 2(e) indicates that there is about $3.4 \mathrm{wt} \%$ DMAI in the final

18 film. The composition of the film can be considered as the mixture of $\mathrm{DMAI}+\mathrm{CsPbI}$,

19 which are actually in the forms of $\mathrm{Cs}_{4} \mathrm{PbI}_{6}$ and $\mathrm{DMA}_{\mathrm{x}} \mathrm{Cs}_{1-\mathrm{x}} \mathrm{PbI}_{3}$ as presented in the XRD

20 results in Figure 2(a). So, if there are $3.4 \mathrm{~g}$ DMAI (equal to $3.4 / 173 \mathrm{~mol}$ ) in the film,

21 the amount of $\mathrm{CsPbI} 3$ should be $96.6 \mathrm{~g}$, equal to $96.6 / 721 \mathrm{~mol}$. 
1 Here we can get the equitions:

$2(3.4 / 173) \mathrm{DMAI}+(96.6 / 721) \mathrm{CsPbI}=\mathrm{m} \mathrm{Cs}_{4} \mathrm{PbI}_{6}+\mathrm{nDMA}_{\mathrm{x}} \mathrm{Cs}_{1-\mathrm{x}} \mathrm{PbI}_{3}$

$3 \mathrm{~m}+\mathrm{n}=96.6 / 721=0.13398(\mathrm{~Pb})$

$44 m+(1-x) n=96.6 / 721=0.13398(C s)$

$5 \mathrm{nx}=3.4 / 173=0.01965(\mathrm{DMAI})$

6 Then $\mathrm{x}$ is approximately $15 \%$.

7

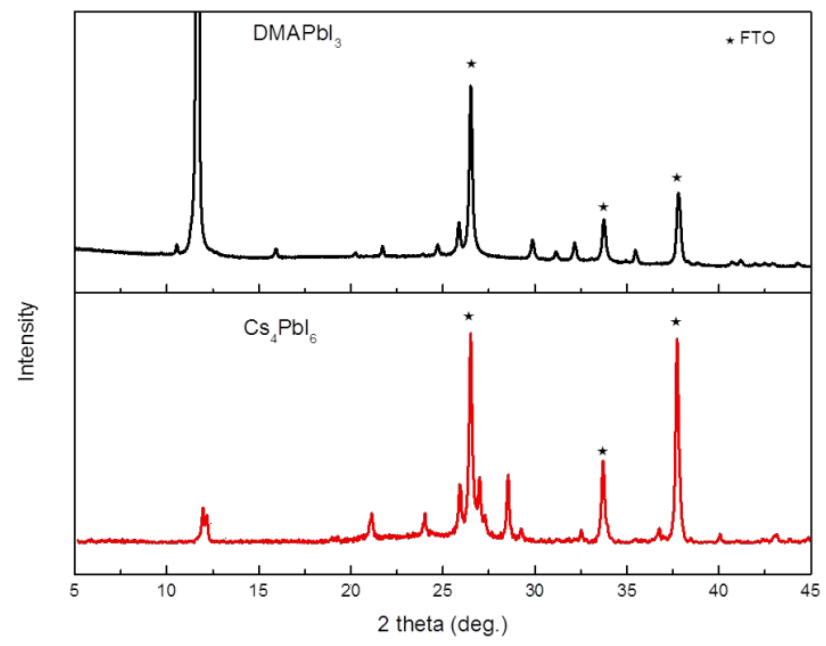

8

Figure $\mathrm{S} 1$. XRD spectra of $\mathrm{DMAPbI}_{3}$ and $\mathrm{Cs}_{4} \mathrm{PbI}_{6}$ films on FTO.

10

a $100^{\circ} \mathrm{C} 15 \mathrm{~min}, 180^{\circ} \mathrm{C} 0 \mathrm{~min}$

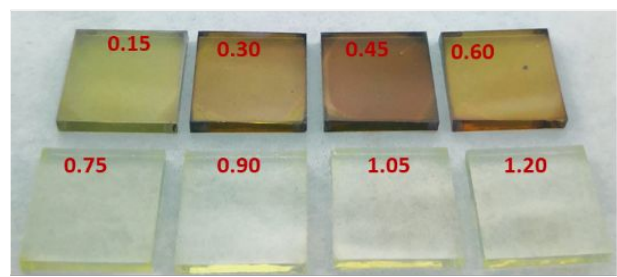

b $100^{\circ} \mathrm{C} 15 \mathrm{~min}, 180^{\circ} \mathrm{C} 15 \mathrm{~min}$

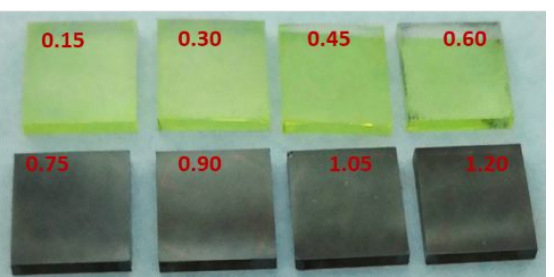


1 Figure S2. Photographs of a series of spin-coated $\mathrm{DMAI} / \mathrm{CsPbI}{ }_{3}$ films after heating at

$2100{ }^{\circ} \mathrm{C}$ for $10 \mathrm{~min}$ (a) and at $180{ }^{\circ} \mathrm{C}$ for $15 \mathrm{~min}(\mathrm{~b})$. The number on the photographs is

3 the mole ratio of DMAI to $\mathrm{CsPbI}_{3}$.

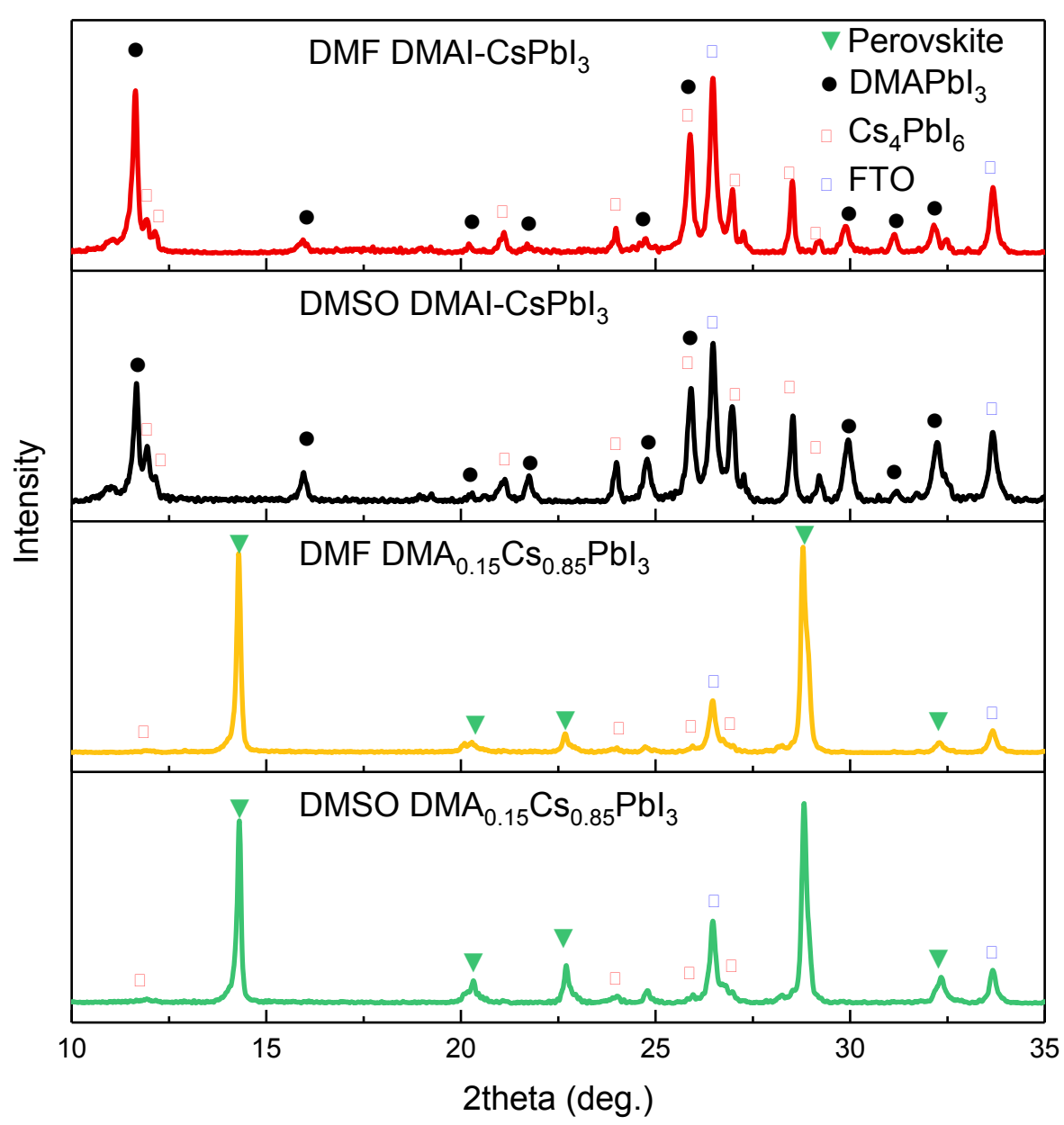

5

6 Figure S3. XRD patterns of the spin-coated DMAI-CsPbI $\mathrm{D}_{3}$ films before and after

7 thermal annealing at $180{ }^{\circ} \mathrm{C}$ for 15 min with DMSO or DMF solvent, respectively. 


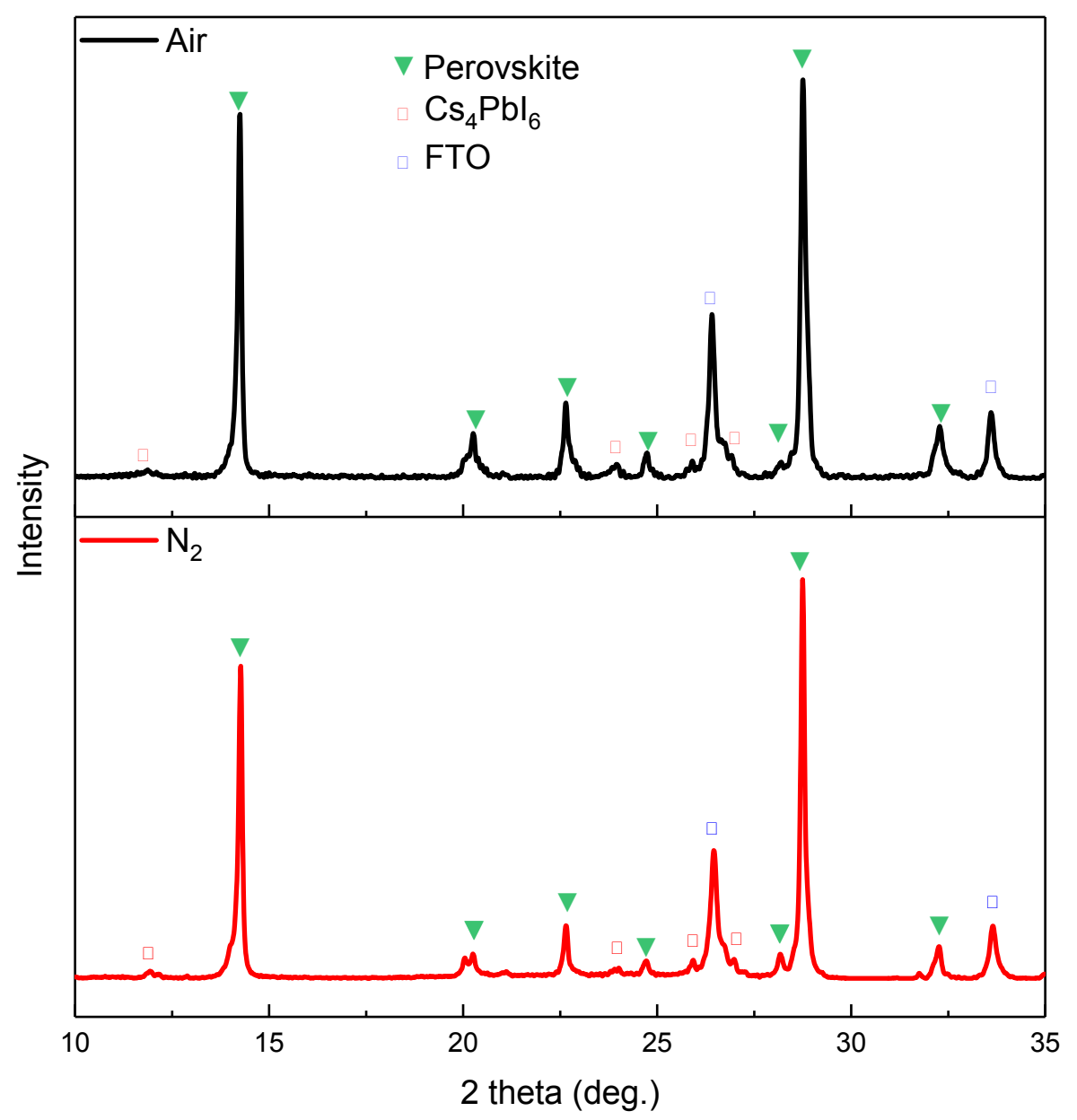

1

2 Figure S4. The comparison of the XRD patterns of spin-coated $\mathrm{DMAI}_{-\mathrm{CsPbI}}$ films

3 after thermal annealing at $180^{\circ} \mathrm{C}$ for $15 \mathrm{~min}$ in air and $\mathrm{N}_{2}$ environment, respectively.

4

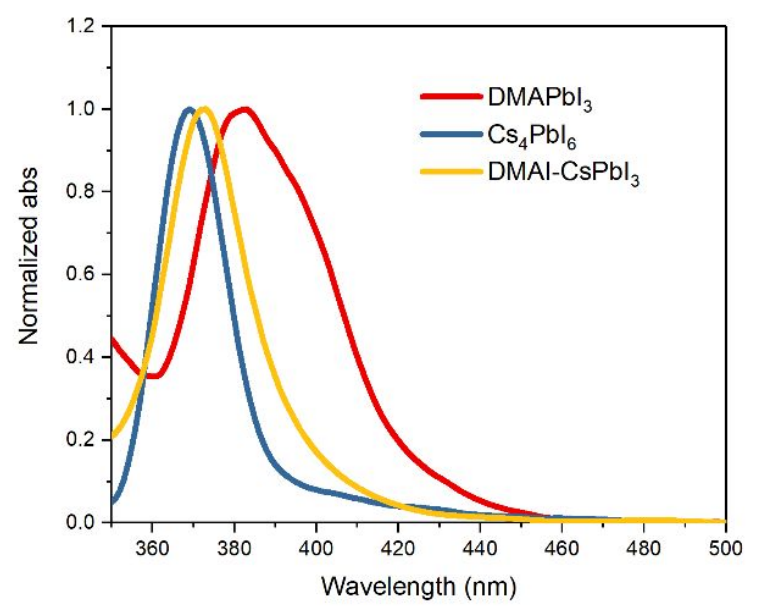


1 Figure S5. Normalized absorption spectra of $\mathrm{DMAPbI}_{3}, \mathrm{Cs}_{4} \mathrm{PbI}_{6}$ and $\mathrm{DMAI}-\mathrm{CsPbI}$ 2 films.

3

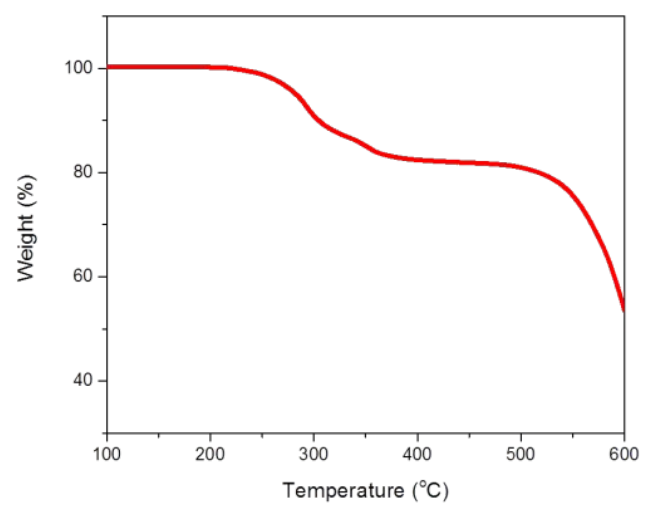

4

5 Figure $\mathrm{S} 6$. TG curve of the $\mathrm{DMAI}-\mathrm{Cs} \mathrm{PbI}_{3}$ powder.

6

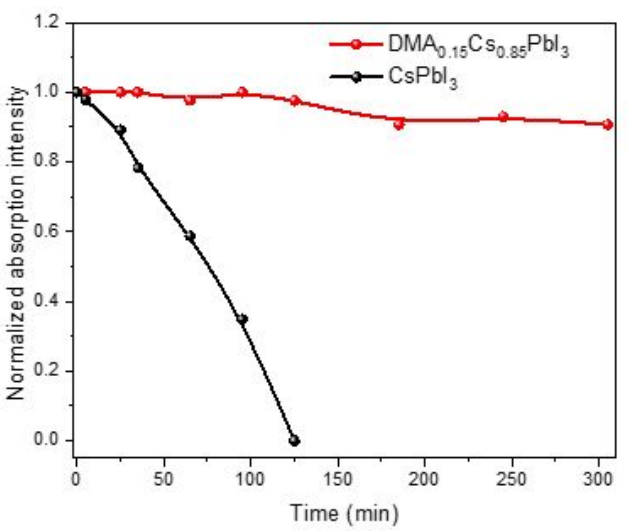

7

8 Figure S7. The normalized absorbance intensity (at $670 \mathrm{~nm}$ ) as a function of time. The

9 films were kept on a hot plate at $120^{\circ} \mathrm{C}$ in $\mathrm{N}_{2}$ environment. 


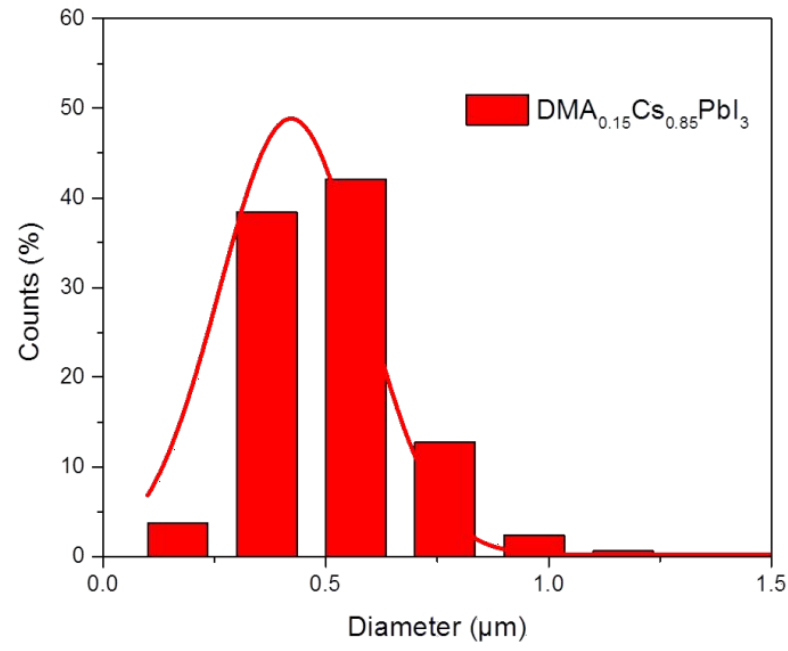

1

2 Figure $\mathrm{S} 8$. Grain size statistics of the $\mathrm{DMA}_{0.15} \mathrm{Cs}_{0.85} \mathrm{PbI}_{3}$ films.

3

4

0.0
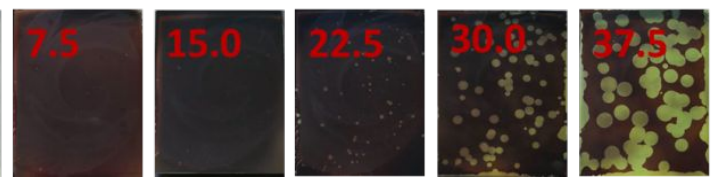

120

5 Figure $\mathrm{S} 9$. Photographs of DMAI-CsPbI ${ }_{3}$ films heated at $180^{\circ} \mathrm{C}$ for different time (min).

6

7
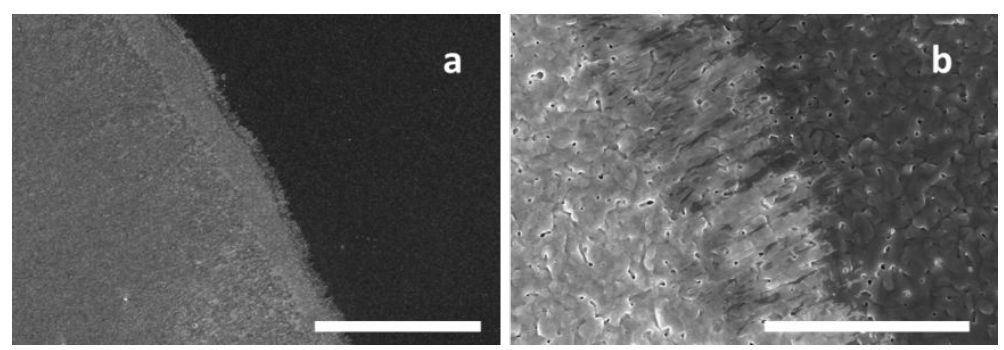

8 Figure $\mathrm{S} 10$. SEM images of the $\mathrm{DMAI}-\mathrm{CsPbI}_{3}$ film after annealing at $180{ }^{\circ} \mathrm{C}$ for $30 \mathrm{~min}$

9 with different magnification. Scale bars in (a) is $100 \mu \mathrm{m}$, in (b) is $10 \mu \mathrm{m}$. 


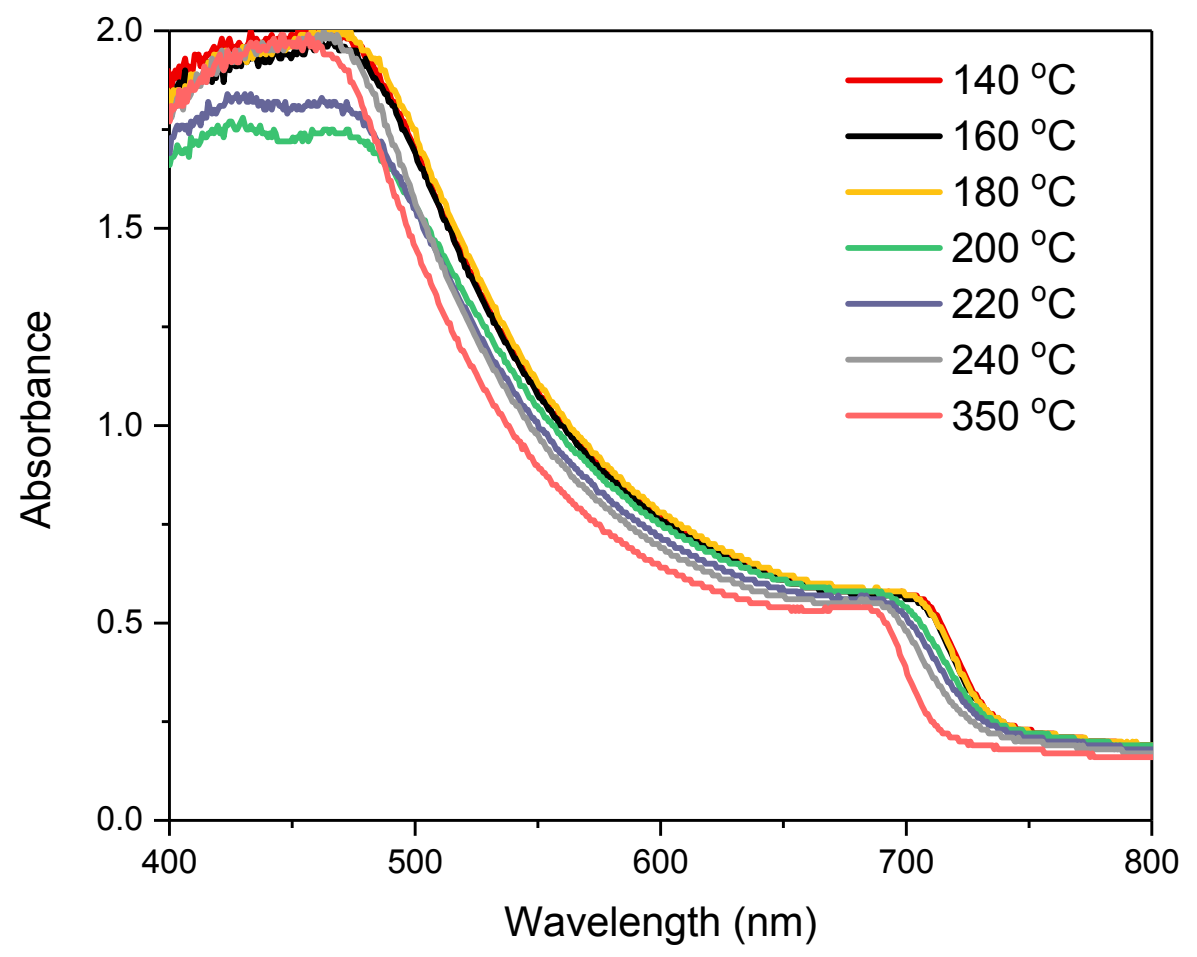

1

2 Figure $\mathrm{S} 11$. UV-Vis spectra of DMAI-CsPbI ${ }_{3}$ films annealed at different temperatures.

3
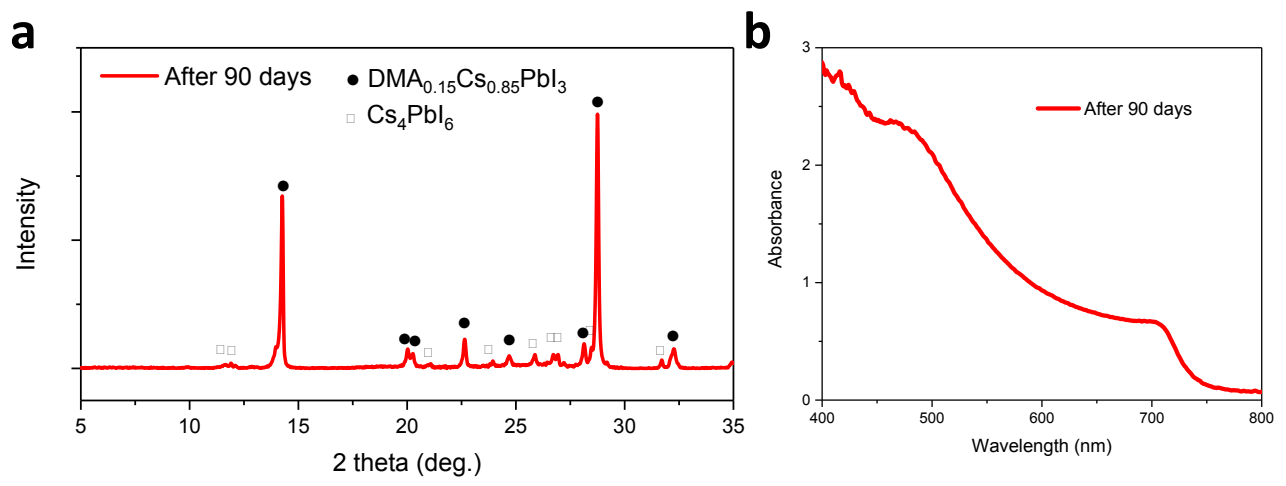

4

5 Figure S12. (a) XRD and (b) UV-Vis absorption spectrum of $\mathrm{DMA}_{0.15} \mathrm{Cs}_{0.85} \mathrm{PbI}_{3}$ film

6 after 90 days storage. The films were stored in dry air with humidity of around $10 \%$ 

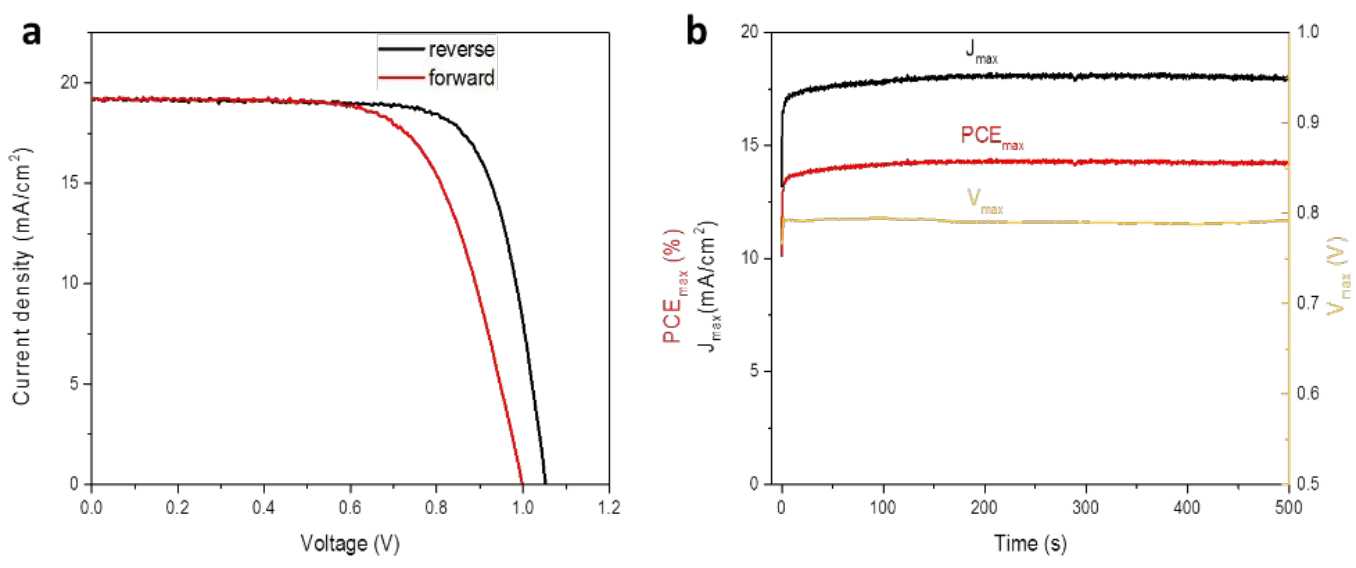

2 Figure S13. (a) The hysteresis property and (b) the maximum power point tracking of

3 the champion $\mathrm{DMA}_{0.15} \mathrm{Cs}_{0.85} \mathrm{PbI}_{3}$ solar cell.

4 